\title{
O leigo e o suporte básico de vida*
}

\author{
LAYPEOPLE AND BASIC LIFE SUPPORT
}

\author{
EL LEGO Y EL SOPORTE BÁSICO DE VIDA
}

\author{
Aline Maino Pergola ${ }^{1}$, Izilda Esmenia Muglia Araujo ${ }^{2}$
}

\begin{abstract}
RESUMO
A capacitação do leigo para o atendimento precoce em situações de emergência e instituição do suporte básico de vida (SBV) é fundamental para salvar vidas e prevenir seqüelas. O objetivo foi identificar o conhecimento dos leigos sobre SBV. Utililizouse entrevista estruturada em linguagem não-técnica. A amostra compreendeu 385 sujeitos, a maioria $(57,1 \%)$ do sexo feminino com ensino médio completo e superior incompleto $(53,7 \%)$. Verificou-se apenas 9,9\% conhecem a manobra de respiração boca-a-boca; $84,2 \%$ conhecem a técnica de compressão torácica externa (CTE), e destes, $79,9 \%$ sabem sua finalidade. Apenas $14,5 \%$ sabem posicionar a vítima para realizar a CTE; 82,4\% referem uma freqüência menor que $60 \mathrm{CTE} /$ minuto. Por não apresentarem adequada informação e fundamentação das etapas do SBV, os leigos podem prestar atendimento incorreto à vítima de emergência, acarretando prejuízos à reanimação.
\end{abstract}

\section{DESCRITORES}

Ressuscitação cardiopulmonar.

Parada cardíaca.

Educação em saúde.

Emergências.

\begin{abstract}
Training laypeople to give first aid in emergency situations and offer basic life support (BLS) is crucial in order to save lives and avoid sequelae. The objective was to identify laypeople's knowledge about BLS. Structured interviews were performed using non-technical language. The sample consisted of 385 subjects. Most (57.1\%) were women with complete secondarylevel education and incomplete higher education (53.7\%). It was verified that only 9.9\% know the mouth-to-mouth ventilation maneuver; $84.2 \%$ knew the chest compression technique (CCT), and $79.9 \%$ of these knew its purpose. Only $14.5 \%$ know how to position the victim to perform CCT; $82.4 \%$ reported a frequency below $60 \mathrm{CCT}$ minute. Since they do not have adequate information and foundations regarding the stages of BLS, laypeople can give incorrect first aid to victims, which can harm resuscitation.
\end{abstract}

\section{KEY WORDS}

Cardiopulmonary resuscitation.

Heart arrest.

Health education.

Emergencies.

\section{RESUMEN}

La capacitación del lego para la atención precoz en situaciones de emergencia e aplicación del soporte básico de vida (SBV) es fundamental para salvar vidas y prevenir secuelas. El objetivo fue identificar el conocimiento de los legos sobre SBV. Se utililizó la entrevista estructurada en un lenguague no técnico. La muestra comprendió 385 sujetos, la mayoría $(57,1 \%)$ del sexo femenino con enseñanza media completa y superior incompleta $(53,7 \%)$; Los que conocen la maniobra de respiración boca a boca son apenas $9,9 \% ; 84,2 \%$ conocen la técnica de compresión toráxica externa (CTE) y de estos, $79,9 \%$ saben su finalidad. Apenas $14,5 \%$ saben posicionar a la víctima para realizar la CTE, $82,4 \%$ refieren una frecuencia menor que $60 \mathrm{CTE} /$ minuto. Por no presentar adecuada información y fundamentos de las etapas del SBV, los legos pueden prestar una aten-ción incorrecta a la víctima de emergencia, ocasionando perjuicios en la reanimación.

\section{DESCRIPTORES}

Resucitación cardiopulmonar.

Paro cardíaco.

Educación en salud.

Urgencias médicas.

* Extraído da pesquisa de Iniciação Científica "O leigo em situações de emergência e o suporte básico de vida", $2005 . \quad{ }^{1}$ Mestranda em Enfermagem, Departamento de Enfermagem, Faculdade de Ciências Médicas, Universidade Estadual de Campinas. Campinas, SP, Brasil. aline_pergola@yahoo.com.br 2 Professora Doutora do Departamento de Enfermagem da Faculdade de Ciências Médicas, Universidade Estadual de Campinas. Campinas, SP, Brasil. iema@fcm.unicamp.br 


\section{INTRODUÇÃO}

As doenças cardiovasculares são uma das principais causas de mortes anuais no Brasil e no mundo ${ }^{(1-4)}$, das quais, a maioria deve-se às cardiopatias isquêmicas ${ }^{(5)}$. A falta de reconhecimento dos sintomas e da valorização da situação encontrada leva a $80 \%$ dos óbitos no ambiente extra-hospitalar e, ocasionam atraso no acionamento de atendimento

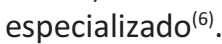

Dessa forma, verifica-se a relevância do atendimento precoce e adequado da parada cardiorrespiratória (PCR) que corresponde a um evento trágico antecipando o fim da vida (morte súbita) ${ }^{(6)}$.

Recentemente um estudo nacional, em hospital público, mapeou o processo de treinamento e os custos em ressuscitação cardiopulmonar (RCP) para técnicos e auxiliares de enfermagem de unidade de terapia intensiva e semiintensiva de adultos, este programa de treinamento visa a qualidade e investimento em pessoal ${ }^{(7)}$.

O suporte básico de vida (SBV) compreende etapas que podem ser iniciadas fora do ambiente hospitalar ${ }^{(1,3,6-8)}$ e rea-lizadas por leigos, devidamente capacitados e informados, aumentando a sobrevida e diminuindo as seqüelas das vítimas de $\mathrm{PCR}^{(1,4,9)}$.

O SBV é definido como a primeira abordagem da vítima e abrange a desobstrução da vias aéreas, ventilação e circulação artificial| $^{(3,9)}$. $O$ acesso precoce ao serviço de emergência, o atendimento avançado e a desfi-brilação precoces são acrescentados a essas manobras ${ }^{(9)}$.

A simples atuação de um leigo que rapidamente reconhece uma PCR e chama por socorro especializado previne a deterioração miocárdica e cerebral. Existem evidências sobre a redução da mortalidade em vítimas de PCR que receberam, de maneira imediata, as manobras de RCP por voluntários e obtiveram a preservação das funções cardíaca e cerebral ${ }^{(3)}$.

Existem também, outros fatores, além da falta de conhecimento, que impedem ou atrasam o socorro adequado. A realização de ventilação boca-a-boca em desconhecidos é um dos motivos de recusa dos socorristas em instituir o SBV ${ }^{(3,9-11)}$. Contudo, acredita-se que a pressão intratorácica gerada pela compressão torácica externa (CTE) é suficiente para deslocar um corpo estranho obstrutor das vias aéreas superiores $^{(9,11)}$. Além disso, a ventilação com pressão positiva não é essencial nos primeiros minutos de RCP, porque o gasping espontâneo mantém as pressões parciais dos gases oxigênio e carbônico próximos aos níveis normais ${ }^{(3,11-12)}$

Deve-se ter em mente que a finalidade principal da RCP é promover a circulação artificial de sangue oxigenado pelo organismo, especialmente para o cérebro e o coração, até as funções vitais retornarem espontaneamente ${ }^{(13)}$.
É fundamental o esclarecimento e a capacitação da população no atendimento à PCR, favorecendo a memorização das etapas do SBV de forma a tornar o processo mecânico e evitar a perda de tempo ao pensar na próxima tarefa a ser executada ou a paralisia pelas emoções que uma situação de emergência desencadeia(9).

A justificativa para esse fato é a relação direta entre o tempo e a preservação das funções miocárdicas e cerebrais, além da redução dos índices de morbidade e mortalidade e a influência na sobrevida e qualidade de vida ${ }^{(4,6,12)}$.

Devido à falta de conscientização e ao medo de reprovação social pelo possível fracasso, ainda há grande falha em se iniciar as manobras básicas, apesar da existência dos cursos de treinamento em SBV para leigos ${ }^{(7)}$.

Dessa forma, se a sobrevida das vítimas de PCR depende da rapidez na instituição adequada das etapas envolvidas no SBV, indaga-se: o que os leigos conhecem sobre o SBV? Como o socorrista leigo executa as manobras de SBV?

Considerando a importância dessa atividade o presente estudo pretendeu verificar qual o conhecimento dos leigos sobre o SBV e as possíveis falhas existentes na realização das manobras, para posterior intervenção.

\section{OBJETIVO}

Identificar o conhecimento sobre o SBV, de uma amostra da população leiga, em uma cidade do interior do estado de São Paulo.

\section{MÉTODO}

Este estudo de caráter descritivo-exploratório foi submetido à apreciação do Comitê Ética em Pesquisa da Instituição, aprovado sob o parecer CEP no 552/2004.

A amostra compreendeu sujeitos com idade igual ou superior a 18 anos, que concordaram em participar da pesquisa, tendo sido realizada nas ruas de uma cidade do interior do estado de São Paulo, devido a grande circulação de transeuntes e a diversidade populacional.

Para calcular o tamanho da amostra, conforme a avaliação das respostas corretas e positivas realizou-se um estudo piloto ( $\mathrm{n}=58$ indivíduos), e considerou-se o maior valor entre todos os resultados obtidos, que resultou em $n=385$ indivíduos, com nível de significância de $5 \%(=0,05)$ e o erro da amostra em $5 \%(d=0,05)$. Foram excluídos indivíduos com idade inferior a 18 anos; com formação na área de saúde (equipe de enfermagem e médicos) ou pertencentes à corporação de bombeiros. A justificativa para a determinação da faixa etária é a legalidade da autorização para entrevista e, dos profissionais citados, espera-se que eles possuam conhecimento sobre o assunto. 
O instrumento de coleta de dados (apêndice I) foi elaborado após a leitura e análise da bibliografia revisada que aborda, basicamente, a cadeia de sobrevivência e a seqüência do SBV $V^{(4,9,11)}$. Dividiu-se em duas partes: identificação e suporte básico de vida, com questões abertas e fechadas (múltipla escolha).

Para a validação de conteúdo, o instrumento foi apreciado por juízes (sete especialistas e seis leigos) quanto à presença ou ausência dos critérios de abrangência, objetividade e pertinência. Os especialistas foram três médicos, três enfermeiras e um bombeiro, os leigos tiveram dois representantes de cada fase do ensino: fundamental, médio e educação superior. Após apreciação o instrumento foi reestruturado segundo as críticas e sugestões manifestadas por eles e aceitas pelas pesquisadoras.

Os dados foram obtidos por meio de entrevista estruturada, após as devidas explicações e assinatura do Termo de Consentimento Livre e Esclarecido (TCLE). Os sujeitos foram interrogados sem a leitura das alternativas, para evitar interferir nas respostas, que foram categorizadas conforme as alternativas estabelecidas e, em seguida, consideradas corretas, parcialmente corretas, incorretas ou ausência de resposta, indicada pela alternativa não sei. As respostas categorizadas como outros correspondem àquelas obtidas e distintas das alternativas estabelecidas. Estão fundamentadas nos dois primeiros elos da corrente de sobrevivência: acesso e RCP precoce as respostas consideradas corretas para as questões da entrevista.

A questão 1 apresenta a alternativa A como correta, a B incorreta e, foi considerada parcialmente correta a resposta categorizada como outros (colocar um espelho em frente ao rosto da vítima).

$\mathrm{Na}$ questão 2 foi considerada correta a alternativa $\mathrm{A}$ e as demais incorretas. As alternativas A e C da questão 3 foram consideradas parcialmente corretas e a alternativa B, correta.

Para as questões 4 e 5 houve apenas agrupamento das respostas semelhantes, positivas ou negativas, pois representam opinião ou experiência particular do entrevistado.

Na questão 6 considerou-se correta toda resposta mencionando reanimação, ressuscitação, retorno dos batimentos cardíacos ou da circulação, para os entrevistados que disseram sim. Na questão 7 foi considerada correta a alternativa A e parcialmente correta a B; as demais foram incorretas.

Na questão 8, a resposta considerada correta foi a alternativa $\mathrm{A}$, por ser mais detalhada do que a $\mathrm{C}$, a qual considerou-se parcialmente correta e as outras, incorretas. Na questão 9 considerou-se correta a resposta 100 vezes por minuto e parcialmente correta até a pessoa voltar ou 80-100 vezes.

Após a categorização e classificação das respostas obtidas, procedeu-se a tabulação eletrônica. Para a análise comparativa utilizou-se o Teste exato de Fisher na comparação da possibilidade de realização da CTE sem ventilação artificial e o conhecimento da finalidade da mesma e, o Teste Qui-Quadrado entre o conhecimento da técnica de respiração boca-a-boca com a possibilidade de realização.

\section{RESULTADOS}

Na apreciação dos juízes especialistas, o instrumento foi considerado abrangente $(85,7 \%)$, objetivo e pertinente (100\%) na identificação. Quanto às questões sobre suporte básico de vida obteve $57,1 \%$ de abrangência e objetividade e, $85,7 \%$ de pertinência. $\mathrm{Na}$ análise dos juízes leigos ocorreu unanimidade nas respostas positivas em relação aos três critérios adotados.

A amostra foi constituída por 385 entrevistados com média de idade de $35,4( \pm 14,55)$ anos, a maioria do sexo feminino $57,1 \%$ e, cursaram até o ensino médio $46,5 \%$ e superior $34,8 \%$. Em relação à distribuição da ocupação dos entrevistados as mais citadas foram: área administrativa 19,7\%, ocupações manuais 15,6\% e área comercial 14\%.

Sobre a verificação da presença de movimentos respiratórios obteve-se, $75,8 \%$ de respostas corretas, $2,6 \%$ parcialmente corretas, $11,7 \%$ incorretas e $9,9 \%$ não souberam responder.

Quanto à realização de manobra para facilitar a respiração, $16,4 \%$ responderam corretamente, 50,1\% incorretamente e $33,5 \%$ não souberam responder. Apenas 16,4\% sabem que levantar o queixo da vítima (alternativa $A$ ) facilita a respiração e $11,5 \%$ acreditam que levantar a cabeça da vítima pode facilitá-la (alternativa B).

As respostas dos leigos a respeito da técnica de respiração boca-a-boca obteve $9,9 \%$ corretas, $41,2 \%$ parcialmente corretas, 9,1\% incorretas e $39,5 \%$ não sabiam responder. A alternativa $D$ foi a mais respondida $(39,5 \%$,$) , enquan-$ to a C obteve $21 \%$.

A possibilidade da realização da respiração boca-a-boca em pessoa desconhecida, sem uso de equipamento de proteção, obteve $42,3 \%$ de respostas afirmativas e $57,7 \%$ de negativas. As justificativas para a não-realização da respiração boca-a-boca encontram-se na Tabela 1 e para a realização na Tabela 2.

Tabela 1 - Distribuição das justificativas dos leigos para não-realização da respiração boca-a-boca em pessoa desconhecida, sem equipamento de proteção - Campinas, SP - 2005

\begin{tabular}{lcr}
\hline Justificativas & N & $\mathbf{\%}$ \\
\hline Possibilidade de transmissão de doenças & 73 & 32,9 \\
Por medo ou nojo & 29 & 13,1 \\
Situação imprevisível & 06 & 2,7 \\
Vítima desconhecida & 03 & 1,3 \\
Por preconceito & 03 & 1,3 \\
Não sei fazer & 77 & 34,7 \\
Não sei por quê & 31 & 14,0 \\
\hline Total & $\mathbf{2 2 2}$ & $\mathbf{1 0 0 , 0}$ \\
\hline
\end{tabular}


Tabela 2 - Distribuição das justificativas dos leigos para a realização da respiração boca-a-boca em pessoa desconhecida, sem equipamento de proteção - Campinas, SP - 2005

\begin{tabular}{lcc}
\hline Justificativas & N & $\mathbf{\%}$ \\
\hline Para salvar & 95 & 58,3 \\
Para ajudar & 25 & 15,3 \\
Por solidariedade & 15 & 9,2 \\
Porque a vida é importante & 06 & 3,7 \\
Não sei por quê & 06 & 3,7 \\
Coloco minhas mãos entre as bocas & 05 & 3,0 \\
Por instinto ou desespero & 04 & 2,4 \\
Por ser mais rápido que o socorro especializado & 03 & 1,8 \\
Não há problema & 03 & 1,8 \\
Caso não haja outro socorrista & 01 & 0,6 \\
\hline Total & $\mathbf{1 6 3}$ & $\mathbf{1 0 0 , 0}$ \\
\hline
\end{tabular}

Na análise comparativa, mais de $50 \%$ dos entrevistados que responderam de forma incorreta sobre a manobra de respiração boca-a-boca a realizariam em vítimas desconhecidas. Dos que conhecem a técnica, 54,8\% também a realizariam em desconhecidos. Dos que relataram não saber, $65 \%$ não a realizariam e, dos $55 \%$ que responderam parcialmente corretos não a realizariam ( $p=0,037$ - QuiQuadrado).

Quanto à possibilidade da realização isolada da CTE, $47,5 \%$ dos entrevistados não a realizariam e $52,5 \%$ a realizariam. As justificativas para as respostas positivas e negativas estão apresentadas nas Tabelas 3 e 4, respectivamente.

Tabela 3 - Distribuição das justificativas para realização de massagem cardíaca isoladamente - Campinas, SP - 2005

\begin{tabular}{lcr}
\hline Justificativas & N & \% \\
\hline Para salvar & 94 & 46,5 \\
Para ajudar & 31 & 15,3 \\
Porque não transmite doenças & 17 & 8,4 \\
Porque tenho maior noção ou é mais fácil & 09 & 4,5 \\
Para reanimar a vítima & 14 & 6,9 \\
Porque é uma alternativa & 09 & 4,5 \\
Não sei fazer & 03 & 1,5 \\
Não sei por quê & 10 & 4,9 \\
Outros & 15 & 7,4 \\
\hline Total & $\mathbf{2 0 2}$ & $\mathbf{1 0 0 , 0}$ \\
\hline
\end{tabular}

Tabela 4 - Distribuição das justificativas dos leigos para não-realização de massagem cardíaca isoladamente - Campinas, SP - 2005

\begin{tabular}{lrr}
\hline Justificativas & N & $\mathbf{\%}$ \\
\hline Porque deve estar associada à respiração boca- a - boca & 32 & 17,5 \\
Pode causar prejuízos à vítima & 09 & 4,9 \\
Não sei fazer & 97 & 53,0 \\
Não sei por quê & 36 & 19,7 \\
Outros & 09 & 4,9 \\
\hline Total & $\mathbf{1 8 3}$ & $\mathbf{1 0 0 , 0}$ \\
\hline
\end{tabular}

Ao verificar o conhecimento dos entrevistados sobre o que é e para que serve a massagem cardíaca, 15,8\% não sabem e $84,2 \%$ referiram saber. Na Tabela 5 encontram-se as respostas obtidas quanto à finalidade da CTE.

Tabela 5 - Distribuição das respostas dos leigos sobre a finalidade da massagem cardíaca - Campinas, SP - 2005

\begin{tabular}{lcc}
\hline Justificativas & N & $\mathbf{\%}$ \\
\hline Reanimação / ressuscitação & 96 & 29,6 \\
Voltar os batimentos cardíacos & 75 & 23,1 \\
Para estimular o coração; fazê- lo voltar a funcionar & 55 & 17,0 \\
Para ajudar na circulação & 32 & 9,9 \\
Para voltar os movimentos respiratórios & 23 & 7,1 \\
Para tratar problemas cardíacos & 08 & 2,5 \\
Ajudar a função cardíaca e pulmonar & 06 & 1,8 \\
Para ritmar o coração & 04 & 1,2 \\
Não sei & 05 & 1,5 \\
Outros & 20 & 6,2 \\
\hline Total & $\mathbf{3 2 4}$ & $\mathbf{1 0 0 , 0}$ \\
\hline
\end{tabular}

$\mathrm{Na}$ análise comparativa entre os entrevistados que realizariam ou não a CTE sem ventilação e o conhecimento deles quanto à sua finalidade, aproximadamente $75 \%$ dos que não a realizariam, conhecem sua finalidade; dos $69 \%$ que a realizariam também conhecem $(p=0,552$ - Exato de Fisher). Entretanto, cerca de $25 \%$ daqueles que não a realizariam isoladamente são os que não a conhecem e $88 \%$ dos que a realizariam mencionaram conhecê-la $(p=0,002$ Qui-Quadrado).

Sobre o posicionamento da vítima para a realização da CTE, as respostas corretas foram $14,5 \%$, parcialmente corretas $71,7 \%$ e incorretas $2,1 \%$. Entre os entrevistados, $11,7 \%$ não sabem.

Considerando a região do corpo na qual se realiza a compressão, 8,8\% responderam corretamente, 63,4\% parcialmente correto, $18,4 \%$ de forma incorreta e $9,4 \%$ não souberam responder.

Em relação ao número de CTE realizadas por minuto, $64,7 \%$ referiram não saber e, 35,3\% responderam afirmativamente. Das respostas obtidas $8,1 \%$ foram parcialmente corretas e $91,9 \%$ incorretas. Nenhum entrevistado conhecia o número de compressões por minuto e $82,4 \%$ acreditavam que essa freqüência seria menor que 60 .

Considerando o total de sete acertos possíveis para as questões da entrevista, 76,6\% obtiveram de zero a dois acertos, $22,6 \%$ de três a cinco e $0,8 \%$ de seis a sete.

\section{DISCUSSÃO}

O sucesso da recuperação da vítima de PCR é a presença de alguém capacitado para iniciar as manobras de RCP, tão logo seja constatada a sua ocorrência ${ }^{(4,9,14)}$. Desta forma, é fundamental a participação da população leiga no atendimento à parada ${ }^{(1,4,9)}$, proporcionando a redução do tempo entre a parada e o início das intervenções ${ }^{(1-2,4,15)}$. 
É, portanto, relevante uma maior conscientização da importância da educação do leigo de modo a propiciar aumento na sobrevida ${ }^{(4)}$, uma vez que o acesso precoce ao serviço especializado pode ser atrasado pela incapacidade das pessoas em diagnosticar a PCR e acionar o socorro(1). Ressalta-se, porém, que essa educação deve ser realizada por pessoal capacitado e de maneira a permitir a retenção e a aplicação do conhecimento quando necessário.

Assim, o esclarecimento e a capacitação da população para o atendimento da PCR, evitando a paralisia do socorrista no momento de decidir qual o próximo passo a seguir, têm importância inquestionável|(3).

Em situações de emergência a avaliação da vítima e seu atendimento devem ser eficazes, permitindo o aumento da sobrevida e a redução de seqüelas ${ }^{(3)}$. $O$ aumento da sobrevida está relacionado com a aplicação das etapas de suporte básico precocemente: reconhecimento da PCR, manobras de RCP e acesso ao suporte avançado de vida ${ }^{(9)}$.

As etapas do SBV compreendem o reconhecimento da parada, as manobras de RCP e o acesso rápido ao suporte avançado de vida ${ }^{(1-4,8,15)}$. Portanto, a rápida ação de um leigo que diagnostica uma PCR e chama por socorro especializado previne as seqüelas miocárdica e cerebral|(3).

O SBV pode ser definido como a abordagem inicial da vítima, realizada por leigos capacitados ou profissionais da saúde, abrangendo a desobstrução da vias aéreas, a ventilação e a circulação artificiais ${ }^{(16)}$.

Para avaliação da respiração, o socorrista deve: VER se há movimentação torácica; OUVIR se há ruído de ar durante a respiração e SENTIR se há fluxo de ar. Para esta avaliação, o socorrista deve aproximar seu ouvido da boca e do nariz da vítima ${ }^{(2-3,13,16)}$. Neste estudo, $75,8 \%$ da amostra respondeu corretamente. Contudo, $14 \%$ manifestaram outras maneiras para se saber se uma pessoa está respirando, dentre elas foi citado verificar a presença de pulso, esse fato indica uma confusão de conhecimento da população leiga, o que pode comprometer o socorro especializado.

Cabe ressaltar que a queda da língua é a causa mais comum de obstrução das vias aéreas em vítima inconsciente e, quando não há evidência de trauma de coluna vertebral, deve-se elevar o queixo de modo a permitir a abertura das vias aéreas ${ }^{(3,16)}$. Entretanto, este estudo revelou que parte dos entrevistados $(33,2 \%)$ não conhece essa manobra e, mais de $50 \%$ responderam incorretamente quando indagados sobre a maneira de facilitar a respiração de uma pessoa inconsciente. Acima de $33 \%$ dos respondentes citaram outras formas de facilitar a respiração, entre elas a respiração boca-a-boca, o que demonstra uma nova confusão no conhecimento.

Não sabe como realizar a respiração boca-a-boca quase $40 \%$ da amostra, $41,2 \%$ conhecem a técnica de forma parcial e menos de $10 \%$ sabem corretamente. Em relação à realização de respiração boca-a-boca em pessoa desconhecida sem uso de equipamento de proteção, $42,3 \%$ dos entrevistados a realizariam, sendo que $73,6 \%$ justificaram ser uma atitude para salvar ou ajudar a vítima. Isso demonstra que considerável parcela da população opta por atender pessoas inconscientes pelo impulso da solidariedade.

Por outro lado, mais de $55 \%$ dos entrevistados não realizariam a respiração artificial em desconhecidos sem proteção. Entre os motivos citados estão a possibilidade de transmissão de doenças $(32,9 \%)$ e por não saber realizar a técnica $(34,7 \%)$.

Observou-se, na análise comparativa, que mais de 50\% dos entrevistados que responderam incorretamente sobre a manobra da respiração boca-a-boca a realizariam em vítimas desconhecidas, e o mesmo percentual dos que acertaram também a realizariam. Por outro lado, os que não sabem (65\%) e os que sabem parcialmente (55\%) não a realizariam ( $p<0,05$ - Qui-Quadrado).

Apesar da respiração de resgate ser uma técnica segura, eficaz e salvar vidas, muitos socorristas deixam de realizar a RCP com medo de contrair doenças infectocontagiosas por meio da respiração boca-aboca $^{(3,9-10)}$. De fato, várias doenças infectocontagiosas podem ser transmitidas durante qualquer contato boca-a-boca, mas, apesar do potencial de transmissibilidade, pouquíssimos casos de contágio durante a execução das manobras de RCP estão registrados na literatura durante 254 anos $^{(10)}$.

Por outro lado, o gasping espontâneo e a CTE são capazes de manter os níveis de oxigênio durante os primeiros minutos da ressuscitação, sem significativa alteração nos índices de sobrevi-

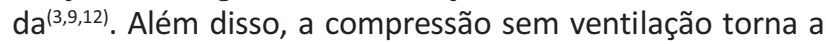
seqüência do SBV mais simples, facilitando o aprendizado, a retenção e a atuação(11). Sem desconsiderar a importância da ventilação artificial durante as manobras de ressuscitação, o socorrista que não estiver disposto a realizá-la deve iniciar, imediatamente, a CTE na vigência de uma PCR, de maneira a não comprometer 0 atendimento ${ }^{(2,8,10-12,17)}$.

Quando indagados sobre a possibilidade de realização da compressão torácica isolada, quase $48 \%$ dos entrevistados não a fariam e, destes $17,5 \%$ justificaram essa atitude pelo fato da compressão estar associada à respiração bocaa-boca. Assim, a população leiga deve ser informada sobre a possibilidade de se realizar a compressão sem ventilação, pois para ela a CTE está ligada a ventilação artificial e, a não realização conjunta dessas duas manobras faz com que nenhuma medida de atendimento seja efetuada, mesmo entre os socorristas leigos treinados ${ }^{(11)}$.

Ao considerar a mesma pergunta, mais de $50 \%$ responderam que realizariam a CTE sem ventilação e, como justificativa, quase $62 \%$, responderam que é uma forma de ajudar ou salvar a vítima. 
A finalidade da RCP é promover artificialmente a circulação de sangue oxigenado pelo organismo evitando os danos causados pela isquemia prolongada, até que retornem as funções ventilatória e cardíaca espontâneas. A compressão é uma manobra básica de reanimação juntamente com a ventilação artificial(12).

Em relação à compressão, a maioria, $84,2 \%$ dos entrevistados, conhece sua finalidade e, destes, quase $80 \%$ responderam corretamente. Daqueles que conhecem a finalidade quase $30 \%$ responderam ressuscitação/reanimação, enquanto $23,1 \%$ relataram que a função da CTE é voltar os batimentos cardíacos, $17 \%$ que é estimular o coração e $9,9 \%$ que auxilia na circulação.

Por outro lado, os conhecimentos sobre a compressão parecem se resumir a sua finalidade, pois mais de $70 \%$ sabem posicionar a vítima para a sua realização de maneira parcialmente correta, uma vez que consideram apenas que a vítima deve estar em decúbito dorsal horizontal. Entretanto, para a realização da CTE eficiente, a vítima deve estar deitada na posição supina sob uma superfície rígida ${ }^{(11,16)}$.

Quanto à região do corpo sobre a qual se realiza a compressão, mais de $60 \%$ dos entrevistados responderam de forma parcialmente correta e $18,4 \%$ incorreta. Considerouse como local adequado para o posicionamento das mãos, dois dedos acima do apêndice xifóide ${ }^{(3,12,16)}$, por ser uma resposta mais detalhada e este estudo ter sido realizado na vigência das diretrizes de $2000^{(4,9)}$. Vale lembrar que de acordo com as novas diretrizes o local é a metade do externo ${ }^{(17)}$.

A freqüência por minuto indicada para realização da CTE é de 100 vezes por minuto ${ }^{(3,9,12,16-18)}$. Nesta pesquisa, quase $65 \%$ não souberam responder e $35,3 \%$ responderam que sabem. Entretanto, daqueles que disseram saber a freqüência cerca de $92 \%$ responderam de maneira incorreta e, $83 \%$ citaram que a freqüência é menor que $60 /$ minuto. Nenhum dos entrevistados soube responder corretamente.

Pelo impulso da solidariedade uma parcela significativa da população, sem capacitação adequada para a prática de primeiros socorros, auxilia vítimas de PCR, desrespeitando as normas estabelecidas no SBV, podendo comprometer a reabilitação pós-parada. Contudo, ainda há grande falha ao iniciar as manobras básicas devido a falta de conscientização e ao medo de reprovação social pelo possível fracasso(8).

\section{CONCLUSÃO}

Pelos resultados obtidos, verificou-se que a população leiga possui conhecimento insuficiente sobre SBV e que, além de incompletos, alguns são incorretos, podendo comprometer o socorro prestado. Sabe verificar a presença de movimentos respiratórios $75 \%$, mas acima de $80 \%$ não sabem realizar manobras que facilitam a respiração. Apenas $10 \%$ conhecem a técnica de realização da respiração bocaa-boca, e $14,5 \%$ sabem posicionar a vítima para a realização da CTE, mas o local do corpo onde é realizada obteve $63,4 \%$ de respostas parcialmente corretas e nenhum sabe a freqüência por minuto. Outro desconhecimento dos entrevistados é a realização da compressão torácica externa isolada da ventilação.

Por não apresentarem adequado entendimento e fundamentação das etapas do SBV, os leigos podem prestar atendimento incorreto à vítima, acarretando prejuízos em sua reanimação, por considerar o conhecimento que possuem correto. Presume-se que muitos socorristas agem apenas pelo sentimento de solidariedade, às vezes, sem possuírem treinamento adequado.

Uma das limitações do estudo foi realizar apenas a abordagem do conhecimento teórico e não ter verificado as habilidades práticas.

Diante da ocorrência de emergências extra-hospitalares e da necessidade de intervenção rápida e adequada, considera-se de fundamental importância a capacitação da população leiga, o que deverá ser objeto de outro estudo.

\section{REFERÊNCIAS}

1. Ferreira DF, Timerman A, Stapleton E, Timerman S, Ramires JAF. Aplicação prática do ensino em emergências médicas. Rev Soc Cardiol Estado São Paulo. 2001;11(2):505-11.

2. Montaña R. Reanimación cardiopulmonar: novedades. Rev Chil Anest [periódico na Internet]. 2005 [citado 2007 jan. 11];34(1): [cerca de 8 p.]. Disponível em: http://www.socanestesia.cl/ rev_anestesia/0506/01-reanimacion.asp

3. Ferreira AVS, Garcia E. Suporte básico de vida. Rev Soc Cardiol Estado São Paulo. 2001;11(2):214-25.
4. Canesin MF, Cardoso LTQ, Soares AE, Moretti MA, Timerman S, Ramires JAF. Campanhas públicas de ressuscitação cardiopulmonar: uma necessidade real. Rev Soc Cardiol Estado São Paulo. $2001 ; 11(2): 512-8$.

5. Zimerman LI. Morte súbita. In: Castro I, organizador. Cardiologia: princípios e práticas. Porto Alegre: Artes Médicas Sul; 1999. p. 595-9.

6. Mesquita ET. Parada cardiorrespiratória e ataque cardíaco: novas estratégias na prevenção e na abordagem inicial. Rev SOCERJ. 1999;12(1):444-5. 
7. Follador NN, Castilho V. O custo do programa de treinamento em ressuscitação cardiopulmonar em um hospital universitário. Rev Esc Enferm USP. 2007;41(1):90-6.

8. Timerman A, Santos ES. Parada cardiorrespiratória. In: Timerman S, Ramires JAF, Barbosa JLV, Hargreaves LHH. Suporte básico e avançado de vida em emergências. Brasília: Câmara dos Deputados, Coordenação de Publicação; 2000. p. 50-67.

9. Ferreira DF, Qüilici AP, Martins M, Ferreira AV, Tarasoutchi F, Timerman S, et al. Essência do suporte básico de vida: perspectivas para o novo milênio: chame primeiro - chame rápido. Rev Soc Cardiol Estado São Paulo. 2001;11(2):209-13.

10. Arend CF. Transmission of infectious diseases through mouth-to-mouth ventilation: evidence-based or emotionbased medicine? Arq Bras Cardiol. 2000;74(1):73-85.

11. Kern KB. Cardiopulmonary resuscitation without ventilation. Crit Care Med. 2000;28(11 Suppl):N86-9.

12. Araujo S, Araujo IEM, Carieli MCM. Ressuscitação cardior-respiratória. Rev Bras Cli Terap. 2001;27(2):80-8.

13. Baeriswyl CT, Ostermann PW, Fuentes RH. Reanimación cardiopulmonar. Rev Chil Anest. [periódico na Internet]. 2003 [citado 2007 jan. 15];32(1):[cerca de 8 p.]. Disponível em: http:/ /www.socanestesia.cl/rev_anestesia/0306/10-reanimacion.asp
14. Eisenburger P, Sterz F, Haugk M, Scheinecker W, Holzer M, Koreny $\mathrm{M}$, et al. Cardiac arrest in public locations: an independent predictor for better outcome? Resuscitation. 2006;70 (3):395-403

15. Isbye DL, Rasmussen LS, Lippert FK, Rudolph SF, Ringsted CV. Laypersons may learn basic life support in 24 min using a personal resuscitation manikin. Resuscitation. 2006; 69(3):435-42.

16. Sociedade Brasileira de Cardiologia. Comissão Nacional de Ressuscitação Cardiorespiratória. Consenso Nacional de Ressuscitação Cardiorrespiratória. Arq Bras Cardiol. 1996;66 (6):375-402.

17. International Consensus on Cardiopulmonary Resuscitation and Emergency Cardiovascular Care Science with Treatment Recommendations. Part 2: Adult basic life support. Resuscitation. 2005;67(2/3):187-201.

18. Zago AC, Nunes CE, Cunha VR, Manenti E, Bodanese LC. Cardiopulmonary resuscitation: update, controversies and new advances. Arq Bras Cardiol [periódico na Internet]. 1999 [citado 2006 out. 10];72(3):[cerca de 23 p.]. Disponível em: http://www.scielo.br/pdf/abc/v72n3/a09v72n3.pdf

\section{APÊNDICE}

INSTRUMENTO DE COLETA DE DADOS

O SUPORTE BÁSICO DE VIDA

Campinas, 1

№

I. Identificação Iniciais:

Idade: anos

Sexo: ( ) F ( ) M Escolaridade:

Procedência: Ocupação:

\section{Suporte básico de vida}

1. Como verificar se a vítima está respirando?

A- ( ) olhando o movimento do peito ou da barriga e/ou aproximando a mão ou o rosto da boca/ nariz da pessoa para sentir a saída do ar

B- ( ) tampa o nariz e vê se ela reage

C- ( ) não sei 
2. Como é possível facilitar a respiração da vítima, caso não haja suspeita de quebra na coluna vertebral?
A- ( ) levantando o queixo da vítima
B- ( ) levantando a cabeça da vítima
C- ( ) abaixando a cabeça da vítima
D- ( ) sentando a pessoa
E- ( ) não sei

3. Como se realiza a respiração boca-a-boca?
A- ( ) inclinando a cabeça da vítima para trás e abrindo a boca. Após encher o peito de ar, assopro na boca da vítima.
B- ( ) inclinando a cabeça da vítima para trás, tampando o nariz e abrindo a boca. Após encher o peito de ar, assopro dentro da boca da vítima, protegendo a minha boca.
C- ( ) assopra dentro da boca da pessoa
D- ( ) não sei

4. Você faria respiração boca-a-boca em uma pessoa desconhecida, sem equipamento de proteção?
() $\operatorname{sim}$
( ) não
Por quê?

5. Você faria massagem cardíaca mesmo não tendo feito respiração boca-a-boca?
() $\operatorname{sim}$
( ) não
Por quê?

6. Você sabe o que é e para que serve a massagem cardíaca?

7. Qual a posição em que deve estar a vítima para que se possa realizar a massagem cardíaca?
A- ( ) deitada de costas, em superfície plana e dura, com a cabeça pouco inclinada para trás
B- ( ) deitada de costas
C- ( ) em qualquer posição
D- ( ) deve permanecer da maneira como desmaiou
E- ( ) não sei

8. Qual é o local do corpo adequado para se realizar a massagem cardíaca?
A- ( ) dois dedos antes do fim do osso que está no meio do peito
B- ( ) sobre o coração
C- ( ) no meio do peito
D- ( ) em qualquer local
E- ( ) não sei

9. Você sabe qual a quantidade de vezes que se realiza a massagem cardíaca, por minuto, em um adulto?
() $\operatorname{sim}$
( ) não
Quantas? 